\title{
EVALUASI NILAI ESTETIKA PADA TAMAN KENCANA DI BOGOR
}

\author{
Nurjannah Hamdani ${ }^{1}$,Cici Nurfatimah ${ }^{2}$, Marselly Dwiputri ${ }^{3}$ \\ ${ }^{1}$ Universitas Indraprasta PGRI, Program Studi Arsitektur \\ nurjannah.hamdani@gmail.com \\ ${ }^{2}$ Institut Sains dan Teknologi Nasional, Progam Studi Arsitektur Lanskap \\ cicinurfatimah@gmail.com \\ ${ }^{3}$ Universitas Indraprasta PGRI, Program Studi Arsitektur \\ Marselly_dwiputri@yahoo.com
}

\begin{abstract}
The park is an green open space thar is managed and used by the community for various outdoor aktivities. Parks are usually arrange to have the value of beauty and comfort for garden users. Beautiful, attractive and harmonious garden landscapes are needed to achieve comfort for the visual connoisseurs of park users. Structuring the park as a green open space that can be used by park users to frequently visit the park. The purpose of evaluation research is to analyze green space as aesthetics. The method used in this study conducted a survey and scoring conducted by calculating the percentage of effectiveness, by calculating the percentage of achievement criteria. The results achieved by the green open space Kencana Park have the value of the effectiveness of the green space function for aesthetics of moderate value, with a value of 63.98\%. This is because the functions of green open space cannot be maximized.
\end{abstract}

Key Words: Aesthetics, Function of Parks, Public Spaces, Parks

\begin{abstract}
Abstrak : Taman merupakan ruang terbuka hijan yang dikelola dan digunakan oleh publik untuk berbagai aktifitas diluar ruangan. Taman biasanya telah ditata oleh pengurus taman agar memiliki nilai keindahan dan kenyamanan bagi penggunan taman. Lanskap taman yang indah, menarik, dan serasi diperlukan untuk mencapai kenyamanan bagi penikmat visual pengguna taman. Penataan taman sebagai ruang terbuka hijau yang indah dapat menarik pengguna taman untuk sering berkunjung ketaman. Tujuan dari penelitian evaluasi dilakkukan untuk analisis fungsi RTH sebagai estetika. Metode yang digunakan pada penelitian ini melakukan survei dan skoring yang dilakukan dengan menghitung persentase efektifitas fungsi, dengan menghitung persentase ketercapaian kriteria. Hasil yang dicapai ruang terbuka hijau Taman Kencana memiliki nilai efektivitas fungsi RTH untuk estetika bernilai sedang, dengan nilai 63,98\%. Hal ini dikarenakan fungsi-fungsi ruang terbuka hijau tidak berperan secara maksimal.
\end{abstract}

Kata Kunci : Estetika, Fungsi Taman, Ruang Publik, Taman

\section{PENDAHULUAN}

Taman dapat dikatakan sebagai ruang terbuka hijau yang sangat erat kaitanya dengan aktifitas manusia sebagai ruang publik. Taman merupakan ruang yang digunakan oleh publik, yang telah ditata oleh pengurus taman agar memiliki nilai keindahan dan kenyamanan bagi penggunan taman. Lanskap yang indah, menarik, dan serasi diperlukan untuk mencapai kenyamanan bagi penikmat visual pengguna taman. penataan taman sebagai ruang terbuka hijau yang indah dapat menarik pengguna taman untuk sering berkunjung ketaman. Menurut (Djamal, 2005), taman merupakan ruang terbuka yang memiliki luasan tertentu, yang didalamnya terdapat berbagai tanaman dan fasilitas , tanaman yang ditanam diantaranya pepohonan, perdu, semak dan rerumputan yang dapat dikombinasikan dengan bahan lainnya. Fasilitas taman sangat diperlukan untuk mendukung kegiatan pengguna taman dan untuk penataan taman sehingga bisa terlihat serasi dengan lingkungan taman tersebut dan menambah nilai estetika dari sebuah taman. Menurut (Nassar, 1988) dan (Simonds, 2006), estetika berhubungan erat dengan visual yang dapat dinilai dengan penampilan suatu objek yang sangat berkaitan dengan segala sesuatu yang berhubungan dengan persepsi. Menurut Nassar (1988), kualitas estetik suatu lanskap dapat memberikan suatu kepuasan tersendiri kepada individu dan secara tidak langsung dapat mempengaruhi perilaku manusia. Vegetasi pada RTH mempunyai empat fungsi yang terdiri atas : 1. Fungsi ameliorasi iklim untuk 
kenyamanan; 2. Fungsi rekayasa lingkungan untuk meningkatkan kualitas fisik lingkungan; 3. Fungsi arsitektural untuk gubahan ruang yang efektif atau aktifitas pengguan atau untuk penggunaan lainnya; 4. Fungsi estetika untuk keindahan. Salah satu RTH publik adalah Taman Kota. Taman kota berupa ruang terbuka yang menyediakan suasana rekreasi di area terbuka bagi masyarakat perkotaan, baik dekat maupun relatif agak jauh dari lingkungan tempat tinggal. Taman Kencana adalah ruang terbuka hijau yang berlokasi di Kota Bogor yang berupa taman publik yang menjadi salah satu tujuan rekreasi warga Bogor dan sekitarnya yang berfungsi sebagai estetika kota, berfungsi sebagai ekologis, fisik dan sosial. Taman dengan luasan area sebesar $5.075 \mathrm{~m}^{2}$ ini, pada awalnya dibangun dengan konsep Rennaisance, yaitu dengan pola simetris. Namun, seiring berjalannya waktu Taman Kencana semakin berkembang jauh dari konsep awal sehingga terjadi ketidak teraturan dalam pemilihan jenis vegetasi yang ditanam serta pola penanaman yang tidak berstruktur, sehingga menghilangkan konsep dari taman tersebut. Evaluasi kualitas estetika RTH adalah proses memahami dengan seksama RTH eksisting dari segenap aspek untuk mengetahui apakah RTH berfungsi dengan baik terkait dengan estetika. Oleh karena itu, tujuan dari penelitian evaluasi dilakkukan untuk analisis fungsi RTH sebagai estetika. Penyusunan rekomendasi untuk meningkatkan efektivitas RTH pada suatu lokasi ke arah RTH yang ideal dengan memanfaatkan segenap potensi sumberdaya yang tersedia.

\section{METODOLOGI}

Lokasi penelitian dilakukan di Taman Kencana, yang berlokasi di Jalan Salak, Kota Bogor, Jawa Barat (Gambar 1). Alat yang digunakan pada penelitian ini berupa kamera digital, alat tulis, meteran, dan komputer dengan software AutoCAD 2010, Adobe Photoshop CS6, Microsoft Word 2007 dan Microsoft Excel 2007.

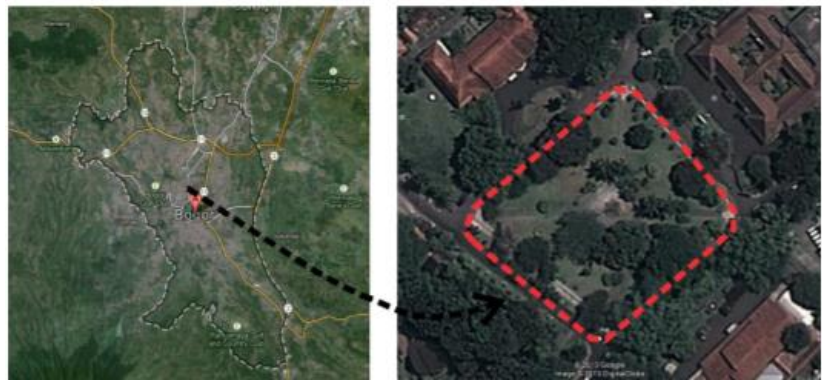

Gambar 1. lokasi taman kencana

Penelitian ini dilakukan dengan metode survey, meliputi pengumpulan data primer dan sekunder, kemudian dilanjutkan dengan analisis data. Setelah pengumpulan data, maka dilakukan analisis fungsi RTH sebagai estetika taman, dengan melakukan penilaian dengan memberi skor setiap item kriteria (beri skor antara 1-10, dengan skor 1: sangat kurang tercapai pada skala seluruh bidang atau garis penanaman. Skor 10: baik sekali dalam pencapaian kriteria pada skala seluruh bidang atau garis penanaman). Menghitung persentase efektifitas fungsi, dengan menghitung persentase ketercapaian kriteria dengan rumus:

Efektifitas fungsi $=\frac{\text { Jumlah skor kriteria semua fungsi }}{\text { Total skor kriteria semua fungsi }} x 100 \%$

Efektifitas RTH = rata-rata\% dari semua fungsi Efektifitas fungsi:

Baik sekali: $100 \%$ kriteria tercapai Baik: $75 \%$ - < $100 \%$ kriteria tercapai Sedang: $50 \%-<75 \%$ kriteria tercapai Kurang: $25 \%-<40 \%$ kriteria tercapai Kurang sekali: $<25 \%$ kriteria tercapai

Pengelompokan fungsi tanaman dilakukan dengan menggunakan standar penilaian berupa kriteria yang dapat dilihat pada Tabel 1 . 
Tabel 1. Kriteria Penilaian Aspek Fungsi Estetika Tanaman

\begin{tabular}{lll}
\hline $\begin{array}{l}\text { Fungsi Kriteria } \\
\text { Estetika }\end{array}$ & $\begin{array}{l}\text { Penilaian di } \\
\text { lapang }\end{array}$ & $\begin{array}{l}\text { Nilai } \\
\text { Ideal }\end{array}$ \\
\hline $\begin{array}{l}\text { Pola penanaman } \\
\text { bersifat estetis }\end{array}$ & $1-10$ & 10 \\
\hline $\begin{array}{l}\text { Pola penanaman } \\
\text { secara massal }\end{array}$ & $1-10$ & 10 \\
\hline $\begin{array}{l}\text { Memberi aksen } \\
\text { berdasarkan warna }\end{array}$ & $1-10$ & 10 \\
\hline $\begin{array}{l}\text { Membingkai } \\
\text { pemandangan (vista) }\end{array}$ & $1-10$ & 10 \\
\hline $\begin{array}{l}\text { Memiliki kesatuan } \\
\text { tema (warna) }\end{array}$ & $1-10$ & 10 \\
\hline $\begin{array}{l}\text { Pola penanaman } \\
\text { memberi } \\
\text { keseimbangan }\end{array}$ & $1-10$ & 10 \\
\hline $\begin{array}{l}\text { Sumber: Wungkar MM (2005), Desyana RD (2011) } \\
\end{array}$
\end{tabular}

\section{HASIL DAN PEMBAHASAN}

Sejarah dan Kondisi Umum Secara historis, kawasan Taman Kencana merupakan bagian dari perkembangan Bogor sebagai kota pada masa kolonial, yang dimulai sejak pemerintahan Baron van Imhoff (Bappeda, 2005). Karakter Kota Bogor sebagai kota kolonial yang perlu dilestarikan, dapat dilihat dari sejarah awal pembentukan Kota Bogor dan pembentukan kawasan permukiman.

Taman Kencana (Van Imhoff Plein) merupakan taman yang dibangun pada 1927 dengan konsep Rennaissance berbentuk geometri dengan dengan axis yang menuju focal point, berupa air mancur di tengah taman. Fungsi utama taman tersebut adalah sebagai penyedia keindahan lingkungan dengan aktifitas rekreasi pasif. Pada masa tersebut, taman ini dipelihara oleh pihak Balai Penelitian Perkebunan dan diperutukan bagi bangsa Eropa yang tinggal di sekitarnya serta pegawai-pegawai Balai Penelitian Perkebunan (Widjaja, 1991). Taman Kencana berlokasi di Kota Bogor yang terletak pada Koordinat 106045'37" s/d 106040'27" BT dan di antara 6032 '30" s/d 6037'30" LS dengan jarak $\pm 56 \mathrm{~km}$ dari Kota Jakarta dan mempunyai ketinggian 190330 mdpl.

Taman Kencana memiliki luas sekitar 5.075 $\mathrm{m} 2$. Taman ini berada di lokasi yang sangat strategis sebagai taman publik karena mudah diakses menggunakan kendaraan pribadi dan angkutan umum. Aksesmenuju Taman Kencana dari arah Utara dapat diakses melalui $\mathrm{Jl}$. Tangkuban Perahu, Jl. Burangrang, dan Jl. Bukit Tunggul. Arah Selatan dapat diakses melalui Jl. Salak, Arah Barat dapat diakses melalui Jl. Ciremai, sedangkan dari arah Timur dapat diakses melalui Jl. Pangrango dan Jl. Sanggabuana. Taman Kencana ini juga dekat dengan ruang publik lainnya yaitu Lapangan Sempur di sebelah Selatan.

\section{Penilaian Fungsi RTH sebagai fungsi yang bernilai estetika}

Penilaian dilakukan berdasarkan kriteria pada (Tabel 1). Sebelum dilakukan penilaian terlebih dahulu Taman Kencana dibagi dalam beberapa segmen (bagian-bagian dari taman), dari pembagian itu di peroleh lima segmen untuk dinilai. berikut hasil penilaian dari fungsi estetika ditampilkan pada (Tabel 2).

Tabel. 2 Penilaian fungsi estetika

\begin{tabular}{ccccccccc}
\hline Segmen & \multicolumn{1}{c}{ Kriteria Penilaian } & Skor $(\%)$ & Kategori \\
\cline { 2 - 7 } & 1 & 2 & 3 & 4 & 5 & 6 & & \\
\hline 1 & 5 & 7 & 8 & 6 & 8 & 7 & 68,3 & Sedang \\
\hline 2 & 3 & 7 & 8 & 6 & 8 & 6 & 63,3 & Sedang \\
\hline 3 & 6 & 7 & 9 & 3 & 9 & 4 & 63,3 & Sedang \\
\hline 4 & 7 & 8 & 8 & 6 & 8 & 4 & 68,3 & Sedang \\
\hline 5 & 3 & 5 & 6 & 3 & 6 & 8 & 51,7 & Sedang \\
\hline \multicolumn{1}{c}{$\begin{array}{c}\text { Rata- } \\
\text { rata }\end{array}$} \\
\hline
\end{tabular}

sumber: Hasil analisis 2017

Secara umum fungsi estetika untuk kelima segmen Taman Kencana adalah SEDANG. Pola penanaman pada kelima segmen secara estetika memiliki nilai sedang. Taman Kencana merupakan taman Rennaisance yang seharusnya berpola simetris, namun kondisi saat ini pola penanaman tidak simetris dan terkesan berantakan. Penanaman vegetasi juga tidak terlalu massal atau dalam kategori sedang di semua segmen. Sebagian penanaman massal pada semak memiliki pola gerombol atau tidak menyambung membentuk garis linear. Kategori aksen warna sebenarnya terdapat nilai yang tinggi di segmen 1, 2, 3 dan 4. Aksen warna yang menonjol adalah ungu dari pohon Jakaranda (Jacaranda acutifolia) dan Bunga Kupu-kupu (Bauhinia purpurea). Warna lain yang menonjol adalah kuning dari pohon Yellow Flame (Pelthoporum pterocarpum) dan Tabebuia Kuning 
(Tabebuia argentea). Warna-warna bunga yang menonjol ini juga menjadikan Taman Kencana memiliki kesatuan tema. Segmen 1, 2 dan 4 memiliki pola penanaman yang baik untuk membingkai vista dari arah luar ke dalam, yaitu ketika pengunjung masuk ke dalam tapak, maka pandangan pengunjung akan langsung diarahkan ke tengah taman oleh Kemuning (Murraya paniculata) yang membentuk bingkai. Yang menjadi vista adalah ornamen rusa di tengah taman.

\section{Rekomendasi}

Rekomendasi Berdasarkan hasil analisis, maka rekomendasi yang sesuai untuk peningkatan kualitas RTH Taman Kencana menjadi RTH yang ideal yang memiliki nilai estetk adalah sebagai berikut: 1. mewujudkan kembali tema taman Inggris/Rennaisance dengan pola penanaman yang simetris dan estetis; 2 . penataan pohon peneduh disesuaikan dengan aktifitas pengguna di tapak dan objek yang dilindungi; 3. menanam jenis tanaman yang memiliki ciri yang kuat yaitu vegetasi berbunga warna ungu, seperti yang ada pada tapak eksisting yaitu Jacaranda acutifolia dan Bauhinia purpurea serta Ruellia mallacosperma sebagai vegetasi identitas; 4. mengkombinasikan pohon dengan semak untuk memaksimalkan fungsi pereduksi polutan; 5. menanam tanaman barrier pada area yang sering difungsikan tempat parkir kendaraan bermotor agar tetap estetis sekaligus terjaga keamanan. Pemilihan tanaman yang direkomendasikan adalah tanaman semak dengan tinggi $<1,5 \mathrm{~m}$ dengan kerapatan daun tinggi; 6 . menanam tanaman border pada area yang berbatasan dengan lalu lintas kendaraan bermotor yang cukup tinggi. Pemilihan tanaman yang direkomendasikan adalah tanaman semak dengan tinggi $<1,5 \mathrm{~m}$ dan kerapatan daun tinggi.

\section{PENUTUP}

\section{Simpulan}

Ruang terbuka hijau Taman Kencana memiliki nilai efektivitas fungsi RTH untuk estetika bernilai sedang, dengan nilai 63,98\%. Hal ini dikarenakan fungsi-fungsi ruang terbuka hijau tidak berperan secara maksimal. Penataan yang tidak estetis menurunkan kualitas visual. Pemeliharaan yang kurang membuat kondisi tanaman menjadi tidak baik. Namun vegetasi di Taman Kencana mampu memberikan keteduhan bagi pengunjung karena bentuk tajuk melebar dan kanopi saling bertemu. Pepohonan yang sudah tumbuh besar memberikan aksen warna yang kuat pada tapak Taman Kencana yaitu Jakaranda (Jacaranda acutifolia), Bunga Kupu- kupu (Bauhinia purpurea), Yellow Flame (Pelthoporum pterocarpum) dan Tabebuia Kuning (Tabebuia argentea).

\section{Saran}

Selanjutnya dapat dilakukan penilaian pada semua kategori penilaian taman .

\section{DAFTAR PUSTAKA}

[Bappeda]. 2005. Dokumenter Perkembangan Tata Ruang Kota Bogor. Bogor: Badan Perencanaan Daerah Kota Bogor.

Desyana RD. 2011. Trend Desain Penanaman pada Lanskap Permukiman Bogor Nirwana Residence [Skripsi]. Bogor (ID): Institut Pertanian Bogor.

Djamal. 2005. Memupuk Tanaman Hias. Jakarta : Penebar Swadaya.

Nassar JL. 1988. Environmental Aesthetic. New York: Cambridge Univ Press.

Simonds, J O. 2006. Landscpae Architecture: A Manual of Site Planning and design. New York: Graw-Hill Book Co.

Widjaja I. 1991. Studi Sejarah dan Pelestarian Taman Kolonial Kota Bogor Kasus Taman Kencana dan Taman Istana Bogor [Skripsi]. Bogor (ID) : Institut Pertanian Bogor. p 83116.

Wungkar MM. 2005. Evaluasi Aspek Fungsi dan Kualitas Estetika Arsitektural Pohon Lanskap Jalan Kota Bogor [Tesis]. Bogor (ID) : Institut Pertanian Bogor. 